\title{
Picosecond X-ray Absorption Spectroscopy of Photochemical Transient Species in Solution
}

\author{
Munira Khalii ${ }^{1}$, Matthew A. Marcus ${ }^{2}$, Amanda L. Smeigh ${ }^{3}$, James K. \\ McCusker ${ }^{3}$, Henry H. W. Chong ${ }^{4}$ and Robert W. Schoenlein ${ }^{4}$ \\ ${ }^{1}$ Department of Chemistry, University of California, Berkeley California 94720, USA \\ Email: munira@berkeley.edu \\ 2 Advanced Light Source, Lawrence Berkeley National Laboratory, Berkeley, California \\ 94720, USA \\ ${ }^{3}$ Department of Chemistry, Michigan State University, East Lansing, Michigan 48824, \\ USA \\ ${ }^{4}$ Materials Sciences Division, Lawrence Berkeley National Laboratory, Berkeley, \\ California 94720, USA
}

\begin{abstract}
A photoinduced $\mathrm{Fe}^{\mathrm{II}}$ spin crossover reaction in solution is studied with ultrafast $\mathrm{x}$-ray absorption spectroscopy. The iron-nitrogen bond lengthens by $0.21 \pm 0.03 \AA$ in the high-spin transient excited state relative to the ground state.
\end{abstract}

Synchrotron-based, ultrafast x-ray absorption spectroscopy (XAS) is a rapidly growing field that is ideally suited to study transient atomic and electronic structural rearrangements during photochemical reactions in solution with high spatial and temporal resolution [1-4]. We report on the structural dynamics accompanying the ultrafast spin crossover (SCO, interconversion between lowand high-spin electronic states) phenomenon in an $\mathrm{Fe}^{\mathrm{II}}$ complex which serves as a prototypical reaction for understanding electron transfer processes in chemistry and biology [5]. Previous studies have relied on steady-state and non-equilibrium measurements to understand the physiochemical properties and the kinetics of the different spin states [6]. Our experiment probes the dynamic relationship between molecular structure and the ultrafast SCO transition in the low-spin complex, $\left[\mathrm{Fe}\left(\operatorname{tren}(\mathrm{py})_{3}\right)\right]\left(\mathrm{PF}_{6}\right)_{2}$, dissolved in acetonitrile solution [7]. Timeresolved $\mathrm{x}$-ray absorption spectra of $\left[\mathrm{Fe}\left(\operatorname{tren}(\mathrm{py})_{3}\right)\right]\left(\mathrm{PF}_{6}\right)_{2}$ are collected following excitation with a 100 fs optical pulse and the results are compared with the steady-state $\mathrm{x}$-ray absorption spectrum of its high-spin analogue, [Fe(tren(6-Mepy) $\left.\left.)_{3}\right)\right]\left(\mathrm{PF}_{6}\right)_{2}$. Transient pump-probe experiments observe that the structural and electronic changes following excitation are complete within 70 ps and the $\mathrm{Fe}-\mathrm{N}$ bond length is increased by $0.21 \AA$ in the photoexcited high-spin state.

The transient XAS measurements were performed in a non-collinear pumpprobe geometry on BL 5.3.1 at the ALS. A $100 \mathrm{fs}, 350 \mu \mathrm{J}, 400 \mathrm{~nm}$ pulse initiated the $\mathrm{Fe}^{\mathrm{II}} \mathrm{SCO}$ transition in a sample consisting of a $0.5 \mathrm{~mm}$ thick free-flowing jet of $0.02 \mathrm{M}\left[\mathrm{Fe}\left(\operatorname{tren}(\mathrm{py})_{3}\right)\right]\left(\mathrm{PF}_{6}\right)_{2}$ dissolved in acetonitrile at room temperature. A single tunable $70 \mathrm{ps} \mathrm{x}$-ray pulse was used as the probe. The laser pump pulse was synchronized to the $\mathrm{x}$-ray pulse so that it preceded it at a particular delay $(\tau)$ at a repetition rate of $1 \mathrm{kHz}$. Both pump and probe pulses were spatially and 

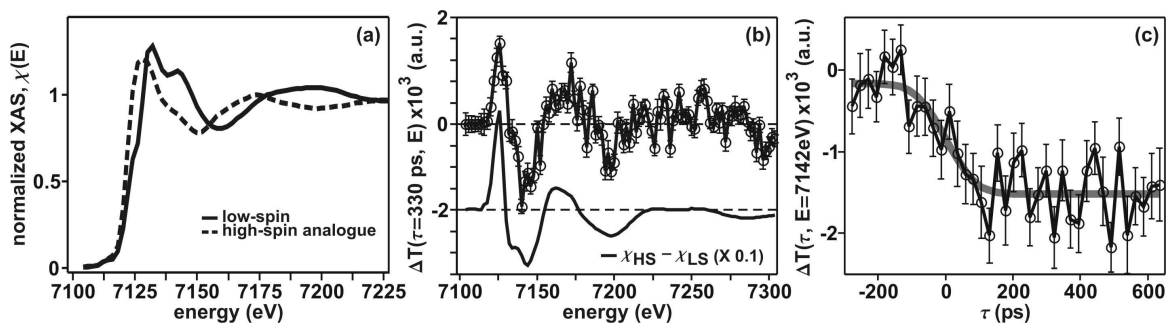

temporally overlapped at the sample and transient $\mathrm{x}$-ray absorption spectra were collected at $2 \mathrm{kHz}$.

Fig. 1. (a) The XANES spectra of $\left[\mathrm{Fe}\left(\operatorname{tren}(\mathrm{py})_{3}\right)\right]\left(\mathrm{PF}_{6}\right)_{2}$ (low-spin) and $[\mathrm{Fe}(\operatorname{tren}(6-\mathrm{Me}-$ py) $\left.)_{3}\right)\left(\mathrm{PF}_{6}\right)_{2}$ (high-spin) compounds in $\mathrm{CH}_{3} \mathrm{CN}$ solution at the Fe K-edge. (b) Transient difference $\mathrm{x}$-ray absorption spectrum at $\tau=330 \mathrm{ps}$. The difference between the steadystate XAS spectra of the high-spin and low-spin compounds is plotted below. (c) Pumpprobe $\mathrm{x}$-ray absorption signal at $7142 \mathrm{eV} . \Delta \mathrm{T}=\left(\mathrm{I}(\tau) \mathrm{I}_{\mathrm{ref}}\right)$, where $\mathrm{I}(\tau)$ and $\mathrm{I}_{\text {ref }}$ refer to the XAS signals with and without the effect of the laser pulse, respectively.

Figure 1(a) displays the XANES (x-ray absorption near edge structure) spectra of $\left[\mathrm{Fe}\left(\operatorname{tren}(\mathrm{py})_{3}\right)\right](\mathrm{PF} 6)_{2}$ and $\left[\mathrm{Fe}\left(\operatorname{tren}(6-\mathrm{Me}-\mathrm{py})_{3}\right)\right](\mathrm{PF} 6)_{2}$ complexes dissolved in $\mathrm{CH}_{3} \mathrm{CN}$. The Fourier transform of the EXAFS (extended x-ray absorption fine structure) spectra show that the average $\mathrm{Fe}-\mathrm{N}$ bond length is $\sim 0.23 \AA$ longer in the high-spin analogue complex with respect to the low-spin complex. The significant elongation of the $\mathrm{Fe}-\mathrm{N}$ bond, reflecting the difference in electronic configuration between the low-spin and high-spin compounds, accounts for all the features observed in the XANES spectra. Figure 1(b) shows the transient difference absorption spectrum of $\left[\mathrm{Fe}\left(\operatorname{tren}\left(\mathrm{py}_{3}\right)_{3}\right)\left(\mathrm{PF}_{6}\right)_{2}\right.$ as a function of the $\mathrm{x}$-ray energy at the Fe K-edge, $330 \mathrm{ps}$ after laser excitation. For comparison, the difference absorption spectrum of the ground-state high-spin complex $\left(\left[\mathrm{Fe}\left(\operatorname{tren}(6-\mathrm{Me}-\mathrm{py})_{3}\right)\right]\left(\mathrm{PF}_{6}\right)_{2}\right)$ and $\left[\mathrm{Fe}\left(\operatorname{tren}(\mathrm{py})_{3}\right)\right]\left(\mathrm{PF}_{6}\right)_{2}$, obtained from the steadystate measurements is plotted below the transient data. The steady-state difference spectrum is scaled by a factor of 0.1 to account for the $10 \%$ photoexcitation of the ground-state species in solution by the laser pump pulse. Figure 2(b) shows the time-evolution of the spectral feature at $7142 \mathrm{eV}$ as a function of the delay between the optical pump and x-ray probe pulses $(\tau)$. The results show a decrease in the amplitude of the spectral feature at $7142 \mathrm{eV}$ following photo excitation of the low-spin compound. The temporal evolution of the difference $x-$ ray signal is fitted by a Gaussian error function (thick solid curve) with a width of $70 \pm 10 \mathrm{ps}$. This width corresponds to the $\mathrm{x}$-ray pulse duration and indicates that the structural evolution following photoexcitation of the low-spin compound, $\left[\mathrm{Fe}\left(\operatorname{tren}(\mathrm{py})_{3}\right)\right]\left(\mathrm{PF}_{6}\right)_{2}$, dissolved in $\mathrm{CH}_{3} \mathrm{CN}$ is complete within the time resolution of our experiment.

We fit the difference XAS spectrum obtained at $\tau=330$ ps to determine the structure of the transient high-spin state. The fitting is performed in $k$ space (data is shown as open circles in Figure 2(a)) from 1 to $7 \AA^{-1}$. The $k$ space fit (solid gray line) is shown in Figure 2(a) and is in good agreement with the data from the differential XAS (open circles). From the fits of the time-and energy- 
resolved transient data, we can summarize that the excited high-spin state of $\left[\mathrm{Fe}\left(\operatorname{tren}(\mathrm{py})_{3}\right)\right]\left(\mathrm{PF}_{6}\right)_{2}$ is characterized by a lengthening of the first coordination sphere by $0.21 \AA$ and that this transformation occurs within 70 ps. This is illustrated in Figure 2(b), which shows the crystal structure of the ground state with arrows indicating the subsequent changes in the structure upon the photoinduced spin change conversion of the molecule in solution.

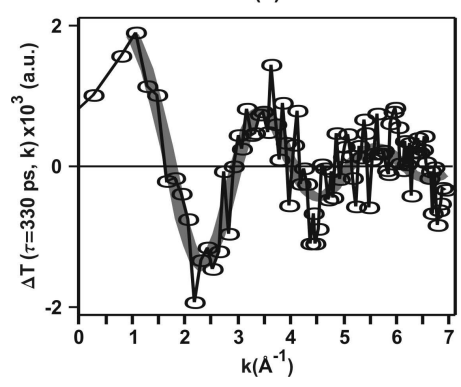

(b)

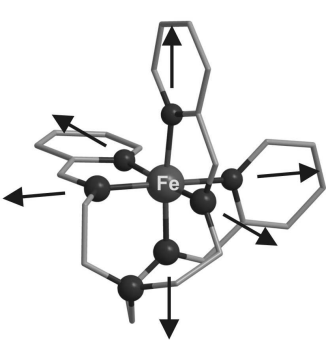

Fig. 2. (a) The transient EXAFS signal (open circles) and the best-fit to the data (gray solid line). (b) The structure of the $\mathrm{Fe}^{\mathrm{II}}$ compound used in this study demonstrating the structural changes that take place during the course of the photoinduced SCO process.

Acknowledgements. This work was supported by the U.S. Department of Energy under Contract No. DE-AC02-05CH11231 at Lawrence Berkeley National Laboratory and under Grant No. DE-FG02-01ER15282 (JKM) at Michigan State University. MK acknowledges the fellowship support of the Miller Institute for Basic Research in Science.

\section{References}

1 Chen, L. X., Jager, W. J. H., Jennings, G., Gosztola, D. J., Munkholm, A. and Hessler, J. P., Science, 292, 262-264 (2001).

2 Saes, M., Bressler, C., Abela, R., Grolimund, D., Johnson, S. L., Heimann, P. A. and Chergui, M., Phys. Rev. Lett., 90, 0474031- 0474034 (2003).

3 Chen, L. X., Annu. Rev. Phys. Chem., 56, 221-254 (2005).

4 Bressler, C., and Chergui, M, Chem. Rev., 104, 1781-1812, (2004).

5 Gütlich, P. and Goodwin, H. A., Spin crossover in transition metal compounds IIII; (Springer-Verlag, Berlin, 2004).

6 Monat, J. E. and McCusker, J. K., J. Am. Chem. Soc., 122, $4092-4097$ (2000)

7 Khalil M., Marcus, M.A., Smeigh, A. L., McCusker, J. K., Chong, H.W.H and Schoenlein, R.W., J. Phys. Chem. A, 110, 38 (2006). 